\title{
A MUDANÇA DAS CATEGORIAS DE ESPAÇO E TEMPO NAS SOCIEDADES COMPLEXAS E SUAS IMPLICAÇÕES NO PROCESSO FORMATIVO NA EDUCAÇÃO SUPERIOR
}

\author{
THE CHANGE OF SPACE AND TIME CATEGORIES IN COMPLEX SOCIETIES AND ITS \\ IMPLICATIONS IN THE TRAINING PROCESS IN HIGHER EDUCATION \\ EL CAMBIO DE LAS CATEGORÍAS DE ESPACIO Y TIEMPO EN LAS \\ SOCIEDADES COMPLEJAS Y SUS IMPLICACIONES EN \\ PROCESSO FORMATIVO EN LA EDUCACIÓN SUPERIOR

\section{Marcio Giusti Trevisol ${ }^{1}$ Altair Alberto Fávero ${ }^{2}$}

\begin{abstract}
RESUMO: O presente artigo pretende discutir como as mudanças das categorias de espaço e tempo nas sociedades complexas tem influenciado nos processos formativos na educação superior. A sociedade moderna, sobretudo, nas últimas décadas se caracterizou por intensas e rápidas mudanças no campo da tecnologia que originaram e transformaram as instituições sociais, a vida e a subjetividade. As mudanças das categorias do tempo e espaço são uma das marcas das sociedades complexas, as quais favorecem a consolidação de um modelo produtivo e uma organização social que primam pela rapidez, produtividade, eficiência e flexibilidade. Neste contexto, quais as influências e implicações deste processo para a Educação Superior? Esta questão é norteadora da pesquisa que possui como objetivo compreender como as mudanças do espaço e do tempo nas sociedades complexas tem motivado a estruturação de novas propostas de organização do processo educativo superior. Metodologicamente trata-se de uma pesquisa exploratória de cunho teórico-bibliográfico que conversa com os autores Giddens, Sennett, Ricardo Antunes e Martha Nussbaum. Estes pesquisadores discutem a problemática contemporânea no âmbito da caraterização sócio históricos das sociedades complexas a partir de suas instituições (socialização indivíduo/sociedade) e da morfologia do trabalho. Assim, a mudança das categorias espaço e tempo nas sociedades complexas vêm influenciando na organização da educação superior ao introduzir uma lógica produtivista - mercadológica da flexibilização e da redução do tempo formativo.
\end{abstract}

PALAVRAS-CHAVE: Educação superior. Tempo e espaço. Formação. Sociedades complexas.

ABSTRACT: This article intends to discuss how the changes of space and time categories in complex societies has influenced the graduation processes in higher education. Modern society, especially in the last decades, has been characterized by intense and rapid changes in the field of technology that originated and transformed social institutions, life and subjectivity. Changes in the categories of time and space are one of the hallmarks of complex societies, which favor the consolidation of a productive model and a social organization that excel for speed, productivity, efficiency and flexibility. In this context, what are the influences and implications of this process for Higher Education? This question guides research that aims to understanding how the changes of space and time in complex societies has motivated the structuring of new proposals for the organization of the higher education process. Methodologically, this is an exploratory theoretical-bibliographic research based on the work of the authors Giddens, Sennett, Ricardo Antunes and Martha Nussbaum. These researchers discuss the contemporary problematic within the socio-historical characterization of complex societies from their institutions (individual / society socialization) and work morphology. Thus, the change of space and time categories in complex societies has influenced the organization of higher education by introducing a productivist - market logic of flexibility and reduction of training time.

Submetido em: 23/04/2018 - Aceito em: 30/05/2018 - Publicado em: 25/06/2018.

\begin{tabular}{l|l|l|l|l|l} 
(C) Rev. Inter. Educ. Sup. & Campinas, SP & v.4 & n.3 & p.648-663 & set./dez. 2018
\end{tabular}


KEYWORDS: Higher education. Time and space. Formation. Complex Societies.

RESUMEN: El presente artículo pretende discutir cómo los cambios de las categorías de espacio y tiempo en las sociedades complejas han influido en los procesos formativos en la educación superior. La sociedad moderna, sobre todo, en las últimas décadas se caracterizó por intensos y rápidos cambios en el campo de la tecnología que originaron y transformaron las instituciones sociales, la vida y la subjetividad. Los cambios de las categorías del tiempo y el espacio son una de las marcas de las sociedades complejas, que favorecen la consolidación de un modelo productivo y una organización social que priman por la rapidez, productividad, eficiencia y flexibilidad. En este contexto, ¿cuáles son las influencias e implicaciones de este proceso para la Educación Superior? Esta cuestión es orientadora de la investigación que tiene como objetivo comprender cómo los cambios del espacio y del tiempo en las sociedades complejas han motivado la estructuración de nuevas propuestas de organización del proceso educativo superior. Metodológicamente se trata de una investigación exploratoria de cuño teóricobibliográfico que charlan con los autores Giddens, Sennett, Ricardo Antunes y Martha Nussbaum. Estos investigadores discuten la problemática contemporánea en el marco de la caracterización socio histórica de las sociedades complejas a partir de sus instituciones (socialización individuo/sociedad) y de la morfología del trabajo. Así, el cambio de las categorías espacio y tiempo en las sociedades complejas vienen influenciando en la organización de la educación superior al introducir una lógica productivista - mercadológica de la flexibilización y de la reducción del tiempo formativo.

PALABRAS ClAVE: Educación Superior. Tiempo y espacio. Formación. Sociedades complejas.

\section{INTRODUÇÃO}

As características da sociedade moderna são resultado de transformações institucionais e organizacionais que tiveram início na Europa no final da Idade Média. Sociólogos clássicos como Durkheim, Marx e Weber nos auxiliam a compreender essas mudanças e seus impactos na estrutura da sociedade. Para as ciências sociais as caraterísticas da modernidade nascente foram modificadas na contemporaneidade fazendo surgir uma sociedade complexa que reconfigura as instituições sociais, rompe com a tradição e com a subjetividade dos indivíduos. Para Cenci e Marcon (2016), a consciência que na atualidade estão sendo delineadas características novas ou mais agudas com relação a outras fases da modernidade, isto é, certas formas de comportamento e de organização social que não foram experimentadas e nem verificadas em épocas anteriores. No contexto das sociedades complexas, as categorias de espaço e tempo são transformadas e aceleradas pelo processo tecnológico e modelo produtivo global próprios do contexto histórico em que estamos inseridos.

$\mathrm{O}$ artigo toma como ponto de partida a intenção de compreender como as mudanças corridas nas sociedades complexas têm influenciado na educação superior. A escritura investigativa se compromete em verificar como a mudança das categorias de tempo e espaço está influenciando no processo formativo superior a partir das referências de Giddens, Sennett, Ricado Antunes e Martha Nussbaum. A metodologia de pesquisa foi exploratória e de cunho teórico-bibliográfico o que nos permitiu dialogar e problematizar os conceitos dos autores para responder e entender o fenômeno de estudo. 
O ensaio é organizado em duas seções, a saber; a) as transformações das categorias de espaço e tempo em sociedades complexas. Para compreender esta condição contemporânea abordaremos a condição de tempo e espaço sob dois ângulos. O primeiro refere-se à questão dos mecanismos de desencaixe apontado por Giddens (2002) e o segundo, as mudanças na organização do trabalho a partir dos estudos elaborados por Sennett (2011) e Ricardo Antunes (2015). Os dois ângulos nos ajudam a pensar a organização do ensino superior nas perspectivas da flexibilização aliado à padronização produtiva do mundo capital; b) no segundo aspecto, abordamos as condições da organização social e de formas produtivas baseadas na flexibilidade do tempo e do espaço. Para compor essa reflexão utilizou-se dos conceitos de pragmática da liofilização flexibilizada de Ricardo Antunes (2009) e as contribuições de Martha Nussbaum (2015) no que tange à redução das áreas das Humanidades e das Artes na educação superior e suas consequências formativas.

Os apontamentos nos permitem observar no cenário da educação superior mudanças que passam da condição tradicional que pressupunha a localidade e um tempo de formação para uma disjunção do espaço e tempo que separa a experiência educativa do seu condicionamento espacial. Torna-se possível experimentar eventos simultâneos, apesar de acontecerem em lugares completamente distintos. O pressuposto tecnológico permite que as experiências formativas possam ser efetivadas a distância. A condição histórica de nosso tempo de alta produtividade com menos tempo e maior globalidade, produz um discurso educativo de enxugamento e flexibilização dos programas para garantir a "saúde" financeira das instituições de ensino superior. Em outras palavras, a mudança das categorias de tempo e espaço nas sociedades complexas influencia não apenas o modo de vida, as instituições ou o modo produtivo capitalista, mas profundamente a organização e funcionamento das instituições educativas. Neste contexto, cabe à universidade pensar e discutir qual a sua missão frente ao discurso mercadológico global.

\section{MUDANÇAS NAS CATEGORIAS DE ESPAÇO E TEMPO NAS SOCIEDADES COMPLEXAS}

Para compreender o sentido e definição de sociedades complexas é necessário que façamos uma breve reconstrução da constituição da sociedade moderna sob o olhar da mudança das categorias de espaço e tempo advindas com o progresso tecnológico. As características da sociedade moderna são resultado de transformações institucionais e organizacionais que tiveram início na Europa no final da Idade Média. Sociólogos clássicos como Durkheim, Marx e Weber nos ajudam a entender os desdobramentos e influências que o alvorecer da modernidade trouxe para a organização da sociedade. No entanto, as explicações sociológicas clássicas da modernidade parecem insuficientes para entender as novas dinâmicas e formas organizacionais possibilitadas pelo desenvolvimento da tecnologia, da ciência, da 
globalização e do modelo produtivo neoliberal que se consolidaram sobretudo nas últimas três décadas.

Para as ciências sociais as características da modernidade nascente foram substituídas ou modificadas na contemporaneidade fazendo surgir uma sociedade complexa. Os pósmodernos como Lyotard (2006) afirmam o fim do projeto de modernidade, por outro lado, pensadores como Habermas (2002) com o conceito de capitalismo tardio e Giddens (2002) de alta modernidade apontam que a fase atual é a expressão de um estágio inacabado ou novo dentro da própria modernidade. O fato é que há um consenso, entre os pesquisadores, que nas últimas três décadas as transformações e mudanças estão ocorrendo em ritmo acelerado e interferindo na organização social. Para Cenci e Marcon (2016, p. 112), “estas, por sua vez, originam novos e diferentes modos de configuração das instituições, da vida social e da subjetividade, o que nos permite compreender as sociedades contemporâneas sob a denominação de sociedades complexas".

Segundo Cenci e Marcon (2016), as sociedades complexas se traduzem por novas formas de organização social que passam pela tecnologia, os meios de comunicação, a globalização da economia, mudanças na política e sua dependência frente aos interesses econômicos, virtualização da vida, mudanças no campo do trabalho, reconhecimento da pluralidade; enfraquecimento da autoridade e das instituições, surgimentos de novos espaços de socialização, movimentos migratórios, crescimento e legitimação do discurso homogêneo do capital financeiro, mercantilização da vida e das instituições de ensino e destruição de certas funções formais em todos os níveis dentre outras.

Estas condições sociais fazem com que as sociedades complexas sejam marcadas pelo pluralismo, diversidade, dinamismo e inter-relações culturais que rompem com a tradição. $\mathrm{O}$ ponto central é reconhecer que nas sociedades tradicionais a socialização dos indivíduos ocorre de forma linear e limitada pelo tempo e pela localidade. As sociedades complexas rompem com essa condição ao instituir, especialmente pela tecnologia e pela globalização, novas formas de socialização que estão para além da noção tradicional de localidade e de tempo. As experiências formativas, nas sociedades complexas, se fazem fora do alcance pessoal, ou melhor, se constroem em um movimento dialético entre o que recebemos pelo contexto de vida pessoal e aquilo que acessamos através da tecnologia.

$\mathrm{O}$ alto dinamismo da sociedade moderna é um aspecto central que aproxima o sociólogo contemporâneo Giddens do conceito de sociedades complexas. No livro Modernidade e identidade (2002), o autor analisa justamente as transformações na concepção de identidade/socialização dos indivíduos a partir do rompimento da ordem tradicional. A dinâmica e pluralidade de experiências requer, segundo Giddens (2002), uma reflexividade do eu. A reflexividade é elemento fundamental na socialização do indivíduo, pois, é entendida pelo autor, como aspecto associado a uma maior autonomia dos sujeitos para fazerem 
escolhas conscientes diante das diversas alternativas que estão colocadas diante de si. Esta condição revela um sentido social como mecanismos de desencaixe.

\begin{abstract}
Além de sua reflexividade institucional, a vida social moderna é caracterizada por profundos processos de reorganização do tempo e do espaço, associados à expansão de mecanismos de desencaixe - mecanismos que descolam as relações sociais e seus lugares específicos, recombinando-os através de grandes distâncias no tempo e no espaço. A reorganização do tempo e do espaço, somada aos mecanismos de desencaixe, radicaliza e globaliza traços institucionais preestabelecidos da modernidade; atua na transformação do conteúdo e da natureza da vida social cotidiana (GIDDENS, 2002, p.10).
\end{abstract}

Os processos de reorganização do tempo e espaço associados aos mecanismos de desencaixe apontados pelo autor são importantes para compreendermos duas condições primordiais em nosso objeto de estudo. O primeiro refere-se ao conceito de socialização do sujeito que se dá por uma relação tensa entre local e global. Neste sentido, qualquer sujeito pode experimentar situações ou acessar informações que estão além do seu espaço de copresença, isto é, a formação do eu não depende somente das instituições tradicionais como a família, a escola e a religião, mas ao contrário, através do dinamismo e da pluralidade pertencentes à alta modernidade (GIDDENS, 2002) o sujeito experimenta uma gama de situações formativas e socializadoras que estão além do espaço e do tempo presencial. Nas sociedades complexas existe uma tensão entre as instituições tradicionais e as novas instituições de formação possibilitadas pelo progresso da tecnologia e pela globalização. $O$ segundo ponto, refere-se aos mecanismos de desencaixe. A globalização com a tecnologia confere aos sujeitos uma multiplicidade de opções. Esta condição "descola as relações sociais de seu lugar específico, recombinando-os através de grandes distâncias do tempo e no espaço" (GIDDENS, 2002, p. 10). Desta forma, o sujeito gradativamente perde seus laços fixos na tradição e passa a vivenciar experiências formativas deslocadas do tempo e do espaço que ocupa. Uma questão importante é pontuar como essa condição social interfere na organização da educação.

Particularmente Giddens (2002), ao formalizar uma teoria dos processos de desencaixe articulado com a reorganização das categorias de espaço e tempo permite tecer apontamento sobre as novas formas de organização da educação superior.

A reorganização de tempo e espaço, os mecanismos de desencaixe e a reflexividade da modernidade supõem propriedades universalizantes que explicam a natureza fulgurante e expansionista da vida social moderna em seus encontros com práticas tradicionais estabelecidas. [...], entretanto de modo geral, o conceito de globalização é melhor compreendido como expressando aspectos fundamentais do distanciamento entre tempo e espaço (GIDDENS, 2002, p. 27).

Os apontamentos do autor nos permitem entender, que nas sociedades complexas o dinamismo, rapidez e flexibilidade impõem uma lógica global que modifica as relações pessoais e as instituições sociais consagradas. Para Cenci e Marcon (2016, p. 119), "a vida neste tipo de sociedade é marcada por descontinuidades, o que pode ser observado em relação 
às mudanças relativas ao tempo e espaço e na aceleração no ritmo de mudanças próprio às instituições modernas". Este fenômeno é observado pelas novas tecnologias, pelo desenvolvimento de redes comunicacionais e pelo mercado global. As novas estruturas trazidas pela globalização e da tecnologia impõem um ritmo para as relações formativas, para o trabalho e para a educação. A lógica da flexibilidade e aceleração do tempo nas sociedades complexas não permite o amadurecimento adequado nos processos educativos. A educação formal caracteriza-se por um processo formativo processual, baseado em um tempo e um espaço específico. A padronização do processo de ensino aprendizagem segundo um modelo produtivo impõe uma lógica de formação em massa e desqualifica uma formação preocupada com os processos.

Neste sentido, parece salutar colocar a questão que todo o processo de socialização e, portanto, qualquer tipo de aprendizagem é derivado da experiência humana que é mediada pela linguagem e pela memória (GIDDENS, 2002, p. 28). A condição apontada evidencia dois efeitos; o primeiro é a descolagem que retira a temporalidade dos signos e das narrativas; o segundo é a instrução de eventos distantes da consciência cotidiana. Muitos dos eventos transmitidos pela mídia ou experimentados pela tecnologia podem ser acessados pelo indivíduo como exteriores ou remotos, mas muitas vezes se infiltram na vida cotidiana tecendo novos significados e novas formas de compreender o mundo. O modo de vida socialmente constituído é marcado por profundas e permanentes transformações que lhe envolvem. Não é possível desconsiderar que nas sociedades complexas o mercado de bens simbólicos e a difusão maciça de informação aliando a uma cultura de massa se tornam agentes socializadores que vão tecendo as identidades dos sujeitos.

As mudanças das categorias de espaço e tempo nas sociedades complexas garantem a perpetuação de uma lógica global e a consolidação de um discurso neoliberal que prima pelo produtivismo rápido, dinâmico e flexível. Sendo assim, por um lado, a globalização se traduz um modelo de socialização dos indivíduos através dos múltiplos acessos a informação, tecnologias e experiências e, por outro, garante a hegemonia do mercado neoliberal. Nas duas situações, nos parece claro, que incidem sobre a formação da subjetividade do eu e uma reconfiguração das instituições para atender as novas regras do mercado de capital. As consequências desse processo são apontadas por Cenci e Marcon (2016, p.113):

Com efeito, um dos fatores mais proeminentes que têm contribuído para isso é a hegemonia de um discurso neoliberal, dogmático na medida em que atribui um poder absoluto às forças de mercado e da tecnociência, desconsiderando um conjunto de elementos e dimensões que são fundamentais para uma compressão mais profunda da vida social contemporânea e suas instituições. Tal discurso tende a reduzir os processos educativos a perspectiva instrumental e mercadológica.

A tese é que as mudanças das categorias de espaço e tempo estão alinhavadas aos interesses do mercado produtivo. Para o modelo empresarial global a produção deve ser eficiente, como menos tempo, maior flexibilidade e maior rentabilidade. Esta condição social tem

\begin{tabular}{l|l|l|l|l|l}
\hline (C) Rev. Inter. Educ. Sup. & Campinas, SP & v.4 & n.3 & p.648-663 & set./dez. 2018 \\
\hline
\end{tabular}


influenciado o ensino superior. Em muitos casos, o ensino superior se tornou uma linha produtiva que se preocupa em formar o maior número de "produtos-alunos", com menos tempo e maior flexibilidade.

Outro ponto importante para compreender a mudança das categorias de espaço e tempo nas sociedades complexas e sua relação com a educação superior, refere-se ao modelo produtivo. A lógica do capital global proporcionou uma morfologia do trabalho quando comparado a décadas anteriores. O trabalho produtivo no modelo neoliberal precisa ser eficiente, flexível, com menos tempo e sem lugar definido. Esta condição contemporânea do trabalho modifica as relações intersubjetivas entre os sujeitos e, consequentemente, fornece novos padrões de organização e funcionalidade para as demais instituições sociais. Neste sentido, qualquer tentativa de discutir a organização do ensino superior nas sociedades modernas deve preocupar-se com a questão do modelo produtivo. Para tanto, faremos uso dos autores Sennett (2011) e Ricardo Antunes (2015) que discutem as mudanças no campo do trabalho a partir da lógica neoliberal e da redução e flexibilização do tempo produtivo.

O pesquisador Richard Sennett, na obra "A corrosão do caráter; consequências pessoais do trabalho no novo capitalismo (2011)", nos fornece um diagnóstico da contemporaneidade ao refletir as mudanças do trabalho e das relações sociais a partir de duas gerações - pai e filho. No processo produtivo, o pai situa-se historicamente no processo produtivo do fordismo que é marcado pelo tempo linear. Já o filho (Enrico) é um trabalhador do modelo Toyotista marcado pela flexibilização do tempo, o dinamismo, a rapidez, pela tecnologia e a globalização. Em ambos os casos, a partir do modelo produtivo que cada um está envolvido se constroem valores para as instituições e para a subjetividade pessoal. No modelo produtivo Toyotista-neoliberal impera a flexibilização do tempo como garantia de produtividade e competência.

Uma maneira de compreender como os elementos do regime flexível se juntam está na organização do tempo no local de trabalho. [...] Se o fexitempo é a recompensa do empregado, também podem o domínio íntimo da instituição. [...] O trabalho é fisicamente descentralizado, o poder sobre o trabalhador mais direto. Trabalhar em casa é a ilha última do novo regime (SENNETT, 2011, p. 68).

A ideia da flexibilização do tempo, pode parecer agradável e sedutora, contudo, esconde um discurso de controle e dominação do trabalhador. Apesar de esta tese ser interessante, nosso compromisso é trazer as discussões de Sennett para o campo das instituições de educação superior. Neste sentido, os conceitos de fluidez, volatilidade e flexibilidade trazidos pelo mundo produtivo do capital se consagram como homogêneos e passam a orientar a organização de instituições tradicionais. A corrosão do caráter que o modelo neoliberal traz sobre a subjetividade do indivíduo também afeta a organização das instituições. Segundo Sennett (2009, p.21), "parece não haver mais longo prazo". A imediatez torna-se o critério capaz de julgar o todo. Segundo Sennett (2011), o curto prazo coloca em questão a possibilidade de subsistência de "laços fortes" em detrimento de "laços fracos". Como dizem

\begin{tabular}{l|l|l|l|l|l} 
(C) Rev. Inter. Educ. Sup. & Campinas, SP & v.4 & n.3 & p.648-663 & set./dez. 2018 \\
\hline
\end{tabular}


os pesquisadores sobre essas questões, o capital ficou impaciente. A projeção de curto prazo impede a construção de relações de amizade, confiança, lealdade e da própria carreira profissional. Neste mesmo processo, o campo educativo superior adotou tais políticas ao flexibilizar o tempo formativo dos estudantes e operar o enxugamento de currículos apoiados na ideológica da máxima eficiência.

O curto espaço de formação impossibilita experiências formativas marcadas pela pesquisa, pela reflexividade e pela condição temporal adequada de desenvolvimento de um pensamento crítico. A lógica produtiva do curto espaço de tempo do mundo empresarial quando absorvida no campo universitário através de políticas educacionais institucionais, impede uma relação forte e profunda de confiança e lealdade entre acadêmico e universidade. O sintoma desta condição é uma descolagem de sentido. $\mathrm{O}$ acadêmico não (se) reconhece e desconhece a universidade como fonte de promoção de conhecimento e transformação aliada à condição contextual da temporalidade histórica que está inserido.

A lógica de enxugamento do ensino superior está adequada ao conceito de "empresa enxuta". Segundo Antunes (2015), a nova fase do capitalismo, sob a era da "empresa enxuta", da empresa toyotista que favorece a consolidação de um discurso de competência e produtividade com menos tempo. A nova morfologia do trabalho, pontuada por Antunes (2015, p. 17), “caracteriza-se pela ampliação do contingente de homens e mulheres terceirizados, subcontratados, part-time, que exercem trabalhos temporários, entre tantas outras formas assemelhadas de informalização do trabalho, que proliferam em todas as partes do mundo".

A flexibilização produtiva em curto espaço de tempo colonizou os discursos e ações práticas, isto é, já fazem parte do pensar e da cultura. Os autores Dardot e Laval (2016), explicam adequadamente essa condição com o conceito de homem-empresa. Segundo os autores, o trabalhador que vende sua força de trabalho ao patrão, em troca recebe um determinado salário, caraterística do período industrial, é sucedido pela figura do homem-empresa, do sujeito empresarial, neoliberal ou neosujeito. Neste sentido, perde-se as dimensões de luta coletiva e incorpora para si um discurso individualista e empresarial como parte da sua identidade.

Neste contexto, o ensino superior é marcado por uma forte influência da ideologia neoliberal. É compreensível percebermos o enxugamento e a flexibilização dos cursos superiores com a prerrogativa de torná-los atraentes para os estudantes e sustentáveis do ponto de vista financeiro e para que sejam aceitos como verdadeiros e legítimos pelos agentes que interagem no campo educacional.

Neste momento, podemos nos perguntar quais as influências do modelo produtivo neoliberal para a educação superior? Como a mudança das categorias de espaço e tempo afeta a organização pedagógica dos cursos superiores? E ainda, quais as possíveis consequências da 
diminuição do tempo formativo para os estudantes e à sociedade como um todo? Estas questões serão discutidas e respondidas na próxima seção do artigo. Por hora, é possível pontuar algumas conclusões: a) as mudanças nas categorias de tempo e espaço nas sociedades complexas alteraram a forma de socialização/individualização dos indivíduos; b) a tecnologia e a globalização desafiam as instituições formativas tradicionais; c) o discurso neoliberal contaminou e redesenhou as instituições sociais, inclusive as educacionais e; d) a lógica produtiva empresarial passou a ser implantada nas universidades o que pode acarretar várias consequências para os ideais do Estado Democrático de Direito.

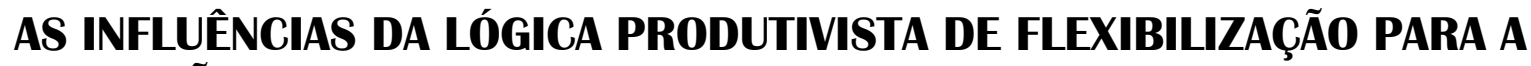 EDUCAÇÃO SUPERIOR}

$\mathrm{O}$ atual contexto de sociedades complexas coloca um conjunto de desafios e reflexões que incidem sobre os processos da educação superior. A fim de responder sobre os impactos da flexibilização do tempo e espaço no campo formativo vamos tecer duas questões centrais que serão o fio condutor. A primeira questão, é entender como ocorre o enxugamento, a flexibilização e a redução do tempo de formação no ensino superior. Na segunda questão pretendemos, sobretudo, discutir as possíveis consequências da consolidação de uma educação superior marcada pela flexibilidade e o enxugamento dos processos de ensino.

Para responder a primeira questão vamos utilizar como base o artigo de Ricardo Antunes titulado "Da pragmática da especialização fragmentada à pragmática da liofilização flexibilizada: as formas da educação no modo produtivo de produção capitalista (2009)". No texto, o autor discute a educação nas diferentes formas produtivas do sistema capitalista. Deste modo, o texto é organizado em três partes. A primeira conceitua o modo de produção a partir das contribuições marxistas. Na segunda parte, realiza uma reconstrução antropológica dos modelos produtivos do capitalismo no século XX e como influenciam a educação. $\mathrm{Na}$ terceira perspectiva o autor localiza a educação dentro dos modos de produção capitalista como uma estrutura de legitimação do capital. Por isso, denomina a educação como pragmática da especialização típica do modelo de produção taylorista-fordista e o curso atual de uma educação flexibilizada pertencente à era produtiva denominada de toyotismo.

Para entender melhor nossa tese faremos uma distinção entre duas formas produtivas e sua relação com a educação. Na forma produtiva Taylorista/fordista, segundo Antunes (2009, p. 30), "a educação é formal, parcelar e hierarquizada. Um tipo de educação que a ideia de Homo sapiens é substituída pela ideia de homo fazer (2009”. Essa ideia é perfeitamente observada nos currículos, no saber especializado das disciplinas, nas escolas e universidades técnicas-profissionalizantes. Neste modelo opera uma organização educacional marcada pelo tempo linear, pela presença do aluno, pela especialização e pela formação de alunos dóceis para o mercado de trabalho. É que "denominamos de pragmática da especialização

\begin{tabular}{l|l|l|l|l|l|}
\hline (C) Rev. Inter. Educ. Sup. & Campinas, SP & v.4 & n.3 & p.648-663 & set./dez. 2018 \\
\hline
\end{tabular}


fragmentada" (ANTUNES, 2009, p. 31). Neste tipo de educação impera a lógica produtiva Taylorista/Fordista em que o tempo e espaço formativo são bem definidos. $\mathrm{O}$ ensino superior é organizado a partir do modelo de presença, currículos definidos e rígidos e tempo de formação linear e modular.

A segunda forma produtiva que influencia diretamente a educação superior é característica das sociedades complexas que "denominaremos doravante de acumulação flexível, volátil, financeirizada e liofilizada" (ANTUNES, 2009, p.31). Essas são as caraterísticas do modelo produtivo toyotista que contemporaneamente atua sobre o ensino superior tornando as universidades empresariais. A adoção da lógica empresarial contamina e deteriora a verdadeira missão do ensino superior. Este é, provavelmente, o grande desafio do ensino superior no século XXI. Mas de que tipo de educação estamos falando na era da flexibilização produtiva? (Parêntese: é importante ressaltar que o modelo produtivo toyotista é derivado de um processo neoliberal, global e tecnológico. A ocorrência das mudanças das categorias de espaço e tempo que afetam a subjetividade e as instituições é decorrente deste contexto social).

Para Antunes (2009), no modo produtivo toyotista a educação também dever ser ágil, flexível e enxuta. Vejamos, que até universidades passaram a ser chamadas de corporativas como ambientes empresariais, inclusive com muitas atividades puramente pragmáticas e pontuais para o mundo do trabalho. A alienação e o estranhamento desse modelo de produção impedem inclusive que muitas universidades tomem seu papel de protagonistas e façam os contrapontos com a sociedade capitalista. Hoje temos muitas universidades que são alienadas e estranhas ao momento histórico que estão inseridas, não conseguem analisar as contradições sociais.

A flexibilidade do mundo produtivo é visualizada, de acordo com Antunes (2009), no ensino superior na expansão de cursos flexíveis, de curto prazo, enxutos e rápidos. O real significado dos cursos superiores é diluído em um sentido puramente mercadológico.

Você fala para alguns milhões e não tem mais o contato presencial. É na verdade uma pragmática flexível para uma sociedade liofilizada (Parêntese: como liofilização não é um termo das ciências sociais, uma explicação rápida. $\mathrm{Na}$ química, liofilizar, significa um processo de temperatura baixa, secar, reduzir as substâncias vivas. O leite em pó é um leite liofilizado. Então você seca a substância viva) (ANTUNES, 2009, p. 31).

O conceito de liofilização utilizado pelo autor nos parece fundamental para traduzir as implicações das transformações das categorias do espaço e tempo. Uma educação superior marcada pela liofilização se traduz por modelos de curto prazo, de produção em massa de estudantes, de enxugamento que gradativamente retira a substância crítica e emancipatória dos cursos superiores. Tomando esse quadro, podemos nos perguntar: quais as implicações da adoção desse modelo educativo no ensino superior para o futuro da sociedade?

\begin{tabular}{l|l|l|l|l|l} 
(C) Rev. Inter. Educ. Sup. & Campinas, SP & v.4 & n.3 & p.648-663 & set./dez. 2018 \\
\hline
\end{tabular}


A autora Martha Nussbaum no livro "sem fins lucrativos: por que a democracia precisa das humanidades (2015)" nos fornece alguns apontamentos importantes para responder a essa pergunta. Na obra, a autora realiza um importante debate sobre a importância das humanidades e das artes para a manutenção e consolidação da democracia. O ponto tratado refere-se ao constante crescimento de estruturas educacionais que privilegiam as conquistas econômicas como o crescimento do produto interno bruto (PIB) em detrimento de uma educação voltada para a formação nas ciências humanas que prima pelo reconhecimento, respeito, inclusão, sensibilidade, ética, autonomia, criticidade etc. Entre esses dois polos, os discursos a favor de uma educação técnica para o mercado têm ganhado força. As consequências são a retirada ou diminuição das áreas e componentes das ciências humanas no ensino superior. Para Nussbaum (2015, p.3):

\begin{abstract}
estamos em meio a uma crise de enormes proporções e de grave significado global. Não, não me refiro à crise econômica global que começou em 2008. Pelo menos naquela época todos sabiam que estavam diante de uma crise, e muitos líderes mundiais agitaram de forma rápida e desesperada para encontrar soluções. Não, refiro-me a uma crise que, como um câncer, passe em grande parte despercebida; uma crise que, no longo prazo, provavelmente será muito mais prejudicial para o futuro dos governos democráticos: uma crise da educação.
\end{abstract}

A preocupação levantada pela autora é decorrente de políticas educacionais que regulam a estruturação dos modelos educacionais que primam pela necessidade única de promover o desenvolvimento econômico dos países. O ponto de encontro entre Martha Nussbaum e Ricardo Antunes se dá na perspectiva que a educação baseada na lógica de mercado promove o enxugamento e a flexibilização do ensino, reconfigurando as categorias de tempo e espaço formativo. Esta flexibilidade de curto prazo promove e valoriza apenas a formação técnica. Esta condição torna-se política educacional em muitos países.

Obcecados pelo PIB, os países - e seus sistemas de educação - estão descartando, de forma imprudente, competências indispensáveis para manter viva a democracia. Se a tendência prosseguir, todos os países logo estarão produzindo gerações de máquinas lucrativas, em vez de produzirem cidadãos íntegros que possam pensar por si próprios, criticar a tradição e entender o significado dos sofrimentos e das realizações dos outros. É disso que depende a democracia (NUSSBAUM, 2015, p. 4).

O enxugamento e flexibilização do ensino superior coloca, dentre os vários problemas, a crise da manutenção dos ideais democráticos. A proposta de um ensino superior marcado pelo modelo produtivo de alto rendimento levou Boaventura Sousa Santos (2010, p. 21), a pontuar a crise da universidade contemporânea como "à eliminação da produção e divulgação livre de conhecimento crítico; e a de pôr a universidade a serviços de projetos modernizadores, autoritários, abrindo ao setor privado a produção do bem público". Visto dessa forma, com o modelo produtivo global as universidades públicas serão obrigadas a concorrer com modelos universitários organizados exclusivamente por interesses de mercado. Por outro lado, 
universidades consolidadas, como por exemplo, as comunitárias passaram a ser pressionadas para aderir à lógica universitária imposta por grandes grupos econômicos que passaram a investir no campo educativo. A desregulação e a livre inciativa de mercado proposta pelo neoliberalismo acabaram por contaminar a organização e as políticas educacionais do ensino fundamental e, sobretudo, do ensino superior.

A adequação do ensino superior à hegemonia dos ideais de mercado fundamenta discursos de administradores públicos que no âmago de tornar o ensino superior mais eficiente, dinâmico e atraente consideram as ciências humanas e as artes como enfeites desnecessários. "No momento em que as nações precisam eliminar todos os elementos inúteis para que se mantenham competitivos no mercado global, elas estão perdendo rapidamente seu lugar nos currículos" (NUSSBAUM, 2015, p.4).

A condição de aceleramento do tempo e espaço formativo no ensino superior agrada a ideologia neoliberal. Não se trata de uma proposta pedagógica consistente ao contrário, atua como condição mercadológica de aumento de lucro de instituições.

De fato, o que poderíamos chamar de aspectos humanistas da ciência humanas - o aspecto construtivo e criativo, e as perspectivas de um raciocínio crítico rigoroso também está perdendo terreno, já que os países preferem correr atrás do lucro de curto prazo por meio do aperfeiçoamento das competências lucrativas e extremamente práticas adequadas à geração de lucro (NUSSBAUM, 2015, p. 4).

Uma educação de curto prazo cerceia uma formação que contemple outras competências. A busca pela competitividade no ensino superior desencadeia um processo de enxugamento de áreas fundamentais para a manutenção e consolidação da democracia e para a consolidação de uma cultura mundial generosa, capaz de tratar, de maneira construtiva os problemas que aparecem no limiar do século.

\footnotetext{
Essas competências estão ligadas às humanidades e às artes: a capacidade de pensar criticamente; a capacidade de transcender os compromissos locais e abordar as questões mundiais como um "cidadão do mundo"; e, por fim, a capacidade de imaginar, com simpatia, a situação difícil em que os outros se encontram (NUSSBAUM, 2015, p. 8).
}

O desenvolvimento de um modelo de ensino baseado na perspectiva de mercado impõe não somente uma padronização, mas reduz gradativamente as humanidades da formação educacional. No mundo capitalista - neoliberal as ciências exatas ou vinculadas à tecnologia são valorizadas e ampliadas, pois são consideradas indispensáveis para uma boa formação. Esta dualidade não significa construir uma separação entre ciências humanas e as ciências exatas. Não se trata de defender, condenar ou de estabelecer uma cruzada entre o bem e o mal. Pelo contrário, uma formação democrática, crítica e emancipada deve contar com uma formação integral do sujeito. O ponto central é adotar um discurso no processo formativo 
superior de mercado que considera apenas como essencial as áreas que desenvolvam as competências para o mundo econômico.

Qualquer país que pretenda afirmar a democracia como modelo de sociedade deve investir na formação para o desenvolvimento da capacidade de raciocinar e refletir criticamente. Segundo Nussbaum (2015, p. 11), "para permitir que as democracias lidem de modo responsável com os problemas que enfrentamos é crucial ter a capacidade de refletir um amplo conjunto de situações locais e globais". A experiência formativa deve ser capaz de possibilitar ao aluno entender situações contextuais a partir de um exercício crítico emancipado de colocar-se no lugar do outro.

Mesmo que os defensores de uma educação superior para o lucro ou uma educação para o desenvolvimento econômico devem pensar e fortalecer uma educação integral. Qualquer economia que pretende ser sólida e sustentável deve investir fortemente em uma formação humanitária. Para Nussbaum (2015, p. 11, "não somos obrigados a escolher entre um modelo de educação que promova o lucro e outra que promova a cidadania plena". A questão é que os defensores da ideologia de mercado adotam uma concepção pobre sobre o papel do ensino superior.

[...] a educação para o crescimento econômico despreza essas áreas da educação da criança porque elas não parecem conduzir ao progresso pessoal ou ao progresso da economia nacional. Por essa razão, no mundo inteiro os cursos de artes e humanidades estão sendo eliminados de todos os níveis curriculares, em favor do desenvolvimento dos cursos técnicos (NUSSBAUM, 2015, p. 23).

Embora a autora esteja nesta citação se referindo à formação das crianças, é perfeitamente permitido ampliar essa condição para o ensino superior. As regras de mercado e desenvolvimento econômico quando adotadas pelo ensino superior imprimem o enxugamento, a formação de curto prazo e flexibilização que permitem consistência econômica às instituições, mas que se revela inapta à formação do cidadão para o mundo democrático.

Neste sentido, as mudanças das categorias de espaço e tempo nas sociedades complexas advindas do progresso tecnológico e aliadas aos ideais de desenvolvimento econômico, contribuíram de forma decisiva para modificar a formação do sujeito, definindo novos ritmos às instituições. No caso das universidades, esta condição aliada à lógica de mercado, contribui para a consolidação de modelos de ensino que são regidos pela diminuição e enxugamento de componentes e áreas de conhecimento. Esta condição favoreceu a formação de curto prazo. Esta situação, coloca-se como um grande desafio no limiar do século XXI para as universidades - o de definir claramente qual sua missão frente à lógica hegemônica de mercado. 


\section{CONSIDERAÇÕES FINAIS}

Nas sociedades complexas o desenvolvimento tecnológico e o avanço científico aliado à lógica neoliberal-global aceleraram o ritmo da vida em todas as suas dimensões. A tensão entre global e local parece ser uma condição estruturante da vida moderna. Então, é possível pontuar que as transformações do tempo e espaço típicos das sociedades complexas transformaram instituições e relações sociais. As experiências formativas dos sujeitos transcendem a presença geográfica de onde estão inseridos. A globalização e as redes de informação, dentre outras formas, fornecem formação e educação que concorrem com as instituições tradicionais como a escola e as universidades.

Essa condição histórica marcada pela lógica da redução do tempo e do espaço é liderada por interesses econômicos globais. A flexibilização produtiva é uma consequência das inovações tecnológicas que possibilitam a materialização na vida cotidiana dos imperativos de enxugamento e eficiência. Esta talvez seja a ideologia mais aceita para legitimar discursos de cortes especialmente nas áreas sociais. Então, podemos constatar que as mudanças das categorias de espaço e tempo, trazidos pelo desenvolvimento tecnológico e ancorados sobre o discurso hegemônico do mercado, têm influenciado as instituições e a subjetividade dos sujeitos.

Neste contexto, as universidades não ficaram imunes. Os interesses privados de mercado passam a contaminar a organização do ensino superior. As lógicas produtivas do mercado, baseados na alta produtividade, eficiência, redução de custos e flexibilidade foram colocadas no ensino superior. No entanto, um processo educativo comprometido e consciente precisa respeitar o tempo adequado para uma boa formação acadêmica. $\mathrm{O}$ que percebemos que quando as universidades assumem como política educacional a lógica empresarial de curto prazo a formação é enxugada, flexibilizada e reduzida a certos componentes curriculares tidos como fundamentais para o sucesso profissional. As estratégicas de educação são marcadas pelo ensino à distância e metodologias ativas que em teoria desqualificam a presença do professor e reduzem quadros de colaboradores.

A condição contemporânea de amplo desenvolvimento da tecnologia aliada à lógica global de mercado, tem levado, segundo Boaventura Souza Santos (2010), a universidade à três crises, a saber: de hegemonia, legitimidade e institucional.

Há uma crise de hegemonia sempre que uma dada condição social deixa de ser considerada necessária, única e exclusiva. A universidade sofre uma crise de hegemonia na medida em que a sua incapacidade para desempenhar cabalmente funções contraditórias leva os grupos sociais mais atingidos pelo seu défice funcional ou Estado em nome deles a procurar meios alternativos de atingir seus objetivos. A crise de legitimidade se apresenta sempre que uma dada condição social deixa de ser consensualmente aceita. A universidade sofre uma crise de 
legitimidade na medida em que se torna socialmente visível a falência dos objetivos coletivamente assumidos. [...] Há uma crise institucional sempre que uma dada condição social estável e auto-sustentada deixa de poder garantir os pressupostos que assegura sua reprodução. A universidade sofre uma crise institucional na medida em que sua especificidade organizativa é posta em causa e se lhe pretende impor modelos organizativos vigentes noutras instituições tidas por mais eficientes (SANTOS, 2010, p. 190).

As três crises da universidade apontadas pelo autor refletem a condição da educação superior nos últimos vinte anos. A condição hegemônica da universidade como produtora de conhecimento especializado e de alta cultura que se fortaleceu desde a idade média se encontra em profunda crise. Na contemporaneidade, as universidades se vêm forçadas a estabelecer novas funções e se adaptar a novas demandas de formação de mão de obra qualificada, de fornecer conhecimentos instrumentais e favorecer uma formação cultural segundo padrões médios. A crise de legitimidade foi provocada pela tensão entre os saberes especializados e as exigências políticas e socais de democratização do ensino superior.

Para atender aos interesses vorazes do mercado global, o ritmo de formação superior é acelerado e, para isso, algumas áreas são literalmente cortadas. A área das humanidades tem sofrido ataques constantes. É observável que em algumas universidades os departamentos de humanidades e artes foram praticamente extintos. Cursos superiores que a presença na grade de disciplinas humanitárias é ínfima ou inexistente. Deste modo, como podemos assegurar uma formação democrática, crítica e emancipatória se gradativamente aceleramos o processo formativo superior com cortes ou assumindo tecnologias que não ajudam a favorecer uma experiência formativa consistente? Parece-nos bastante salutar apontar que no aspecto formativo estamos passando de um modelo educacional baseado na linearidade e tradição para um modelo espelhado na flexibilidade e dinamismo.

Portanto, no tocante à temporalidade das sociedades complexas as universidades devem assumir o compromisso de definir sua missão. O enfrentamento da lógica produtivista, flexível e reducionista deve ser um imperativo assumido pelo ensino superior. O antídoto é formar intelectuais orgânicos (Gramsci), capazes de fazer o enfrentamento. O ensino superior não deve ser uma extensão da ideologia neoliberal. Por isso, o processo formativo no ensino superior não deve ser guiado por enxugamentos ou pela flexibilização produtiva, sob pena de formarmos uma geração inapta para pensar os grandes problemas sociais.

\section{REFERÊNCIAS}

ANTUNES, Ricardo. Da pragmática da especialização fragmentada à pragmática da liofilização flexibilizada: as formas da educação no modo produtivo de produção capitalista.

Germinal: Marxismo e educação em debate, Londrina, v.1, n.1, p.25-33, jun.2009. 
ANTUNES, Ricardo. O caracol e sua concha: ensaios sobre a nova morfologia do trabalho. São Paulo: Bontempo, 2015.

CENCI, Ângelo Vitório; MARCON. Telmo. Sociedades complexas e desafios educativos: individualização, socialização e democracia. In: MÜHL, Eldon Henrique; DALBOSCO, Cláudio Almir; CENCI, Ângelo Vitório (Org.). Questões atuais de educação: sociedade complexa, pensamento pós-metafísico, democracia e formação humana. Ijuí: EdUnijui, 2016.

DARDOT, Pierre; LAVAL, Christian. A nova razão do mundo: ensaios sobre a sociedade neoliberal. São Paulo: Boitempo, 2016.

GIDDENS, Anthony. Modernidade e identidade. Rio de Janeiro: Jorge Zahar, 2002.

HABERMAS, Jurgen. A crise de legitimidade no capitalismo tardio. Rio de Janeiro: Tempo Brasileiro, 2002.

LYOTARD, Jean-François. A condição pós-moderna. 9. ed. Rio de Janeiro: José Olympio, 2006.

NUSSBAUM, Martha Craven. Sem fins lucrativos: por que a democracia precisa das humanidades. São Paulo: Martins Fontes, 2015.

SANTOS. Boaventura de Sousa. Pela mão de Alice: o social e o político na pósmodernidade. 13.ed. São Paulo: Cortez, 2010.

SENNETT, Richard. A corrosão do caráter: consequências pessoais do trabalho no novo capitalismo. 16. ed. Rio de Janeiro: Reocord, 2011.

\footnotetext{
Sobre os autores

${ }^{1}$ Marcio Giusti Trevisol

E-mail: marcio.trevisol@ unoesc.edu.br

Universidade do Oeste de Santa Catarina e Universidade de Passo Fundo - Brasil

Doutorando pela Universidade de Passo Fundo [UPF].

${ }^{2}$ Altair Alberto Fávero

E-mail: altairfavero@gmail.com

Universidade de Passo Fundo - Brasil

Doutor em Educação pela Universidade Federal do Rio Grande do Sul [UFRGS].
} 